\title{
Original
}

\section{Microvascular Density Measurements and Clinical Pathological Analyses of Breast Cancer Tumors}

\author{
Yuko Date ${ }^{1)}$, Nobuyuki OHIKE ${ }^{1)}$, Hiromi Date ${ }^{1.2)}$, \\ Kenya SuZukI ${ }^{2)}$, Terumasa Sawada ${ }^{2)}$ and Toshio Morohoshi ${ }^{1)}$
}

\begin{abstract}
In this study, we measured microvascular densities using two types of vascular endothelial markers, CD34 and nestin, and performed clinical pathological analyses of breast cancer tumors. The subjects included 144 primary breast cancer patients who had undergone surgical resection. Microvascular densities were obtained by randomly selecting three fields of the tumor margins of CD34-and nestin-immunostained samples under high magnification and adding the numbers of positive blood vessels from these fields together. Both CD34 and nestin immunostaining revealed that the microvascular density was higher in patients with lymph node metastases, distant metastases, and lymphatic vessel invasion compared to those without. Although no significant correlation was observed between microvascular density and age, significant correlations were detected between microvascular density and tumor diameter, nuclear grade $(\mathrm{NG})$, and hormone receptor expression. Moreover, a significant decrease in overall survival was observed in cases with high microvascular densities compared to low density cases as measured by CD34 and nestin. The results of this study suggest that microvascular densities in breast cancer tumors may reflect the metastatic growth potential of the tumor or the prognosis of a patient. No obvious differences were observed between CD34 or nestin, the two vascular endothelial markers used to measure microvascular densities in this study.
\end{abstract}

Key words : breast cancer, neovascularization, microvessel density, CD34, nestin

\section{Introduction}

The correlation between tumor proliferation and neovascularization has been studied in various carcinomas ever since it was reported by Folkman ${ }^{1)}$ in 1971 . Neovascularization is also considered to be closely associated with the proliferation/metastasis of tumors in breast cancer, and some reports have suggested the possibility of using this as an independent prognostic factor $^{2-12)}$.

As an assessment method that reflects the degree of neovascularization, the microvascular density of a tumor is often measured in tissue sections obtained from immunostained sam-

1) First Department of Pathology, Showa University School of Medicine, 1-5-8 Hatanodai, Shinagawa-ku, Tokyo 1428555, Japan.

2) Department of Surgery, Division of Gastroenterological and General Surgery, Showa University School of Medicine. 
ples. Vascular endothelial markers are usually used to clarify blood vessels. Many reports have stated that higher microvascular densities are correlated with higher metastatic rates and poor prognoses in breast cancer patients ${ }^{2-12)}$, a situation similar to that found in other carcinomas. In contrast, some studies have reported that there is no correlation between microvascular density and metastasis or prognosis ${ }^{5,11,13-15)}$. One of the reasons for this discrepancy is the use of different antibodies for immunostaining, and differences in the sites used to measure the microvascular density. With this in mind, Kato et al ${ }^{16)}$ measured microvascular densities at three different sites-the tumor margins, tumor centers, and areas where microvessels are gathered-using the Factor VIII vascular endothelial marker, and reported that measurements taken at the tumor margins were useful for evaluating the significance of neovascularization.

In this study, we measured microvascular densities at the tumor margins using the vascular endothelial markers CD34 and nestin in breast cancer tumor resection samples, and assessed the possibility of a correlation between microvascular density and tumor metastasis and patient prognosis.

\section{Subjects and Methods}

\section{Subjects}

One hundred and forty-four patients who had undergone surgical resection of primary breast cancer at our hospital during the two-year period from 1998 to 1999 were included in this study (Table 1). Treatments were not administered to any of the patients prior to the operation, and post-operational adjuvant therapy was performed according to the operational method and the stage of the disease. The mean observation period for these patients was 68 months. In April 2005, there were 115 surviving patients, 24 deaths, and 5 unknown cases. Among the deaths, 20 were due to breast cancer, and 4 were associated with other causes.

\section{Methods}

Thin sections (thickness : $3 \mu \mathrm{m}$ ) were prepared for immunohistochemical studies from formalin-fixed paraffin-embedded blocks containing tumor margins. Immunostaining was performed using the ChemMate EnVision Detection kit (DakoCytomation, Denmark). The anti-human CD34 monoclonal antibody (1:50; QBEnd10, DakoCytomation, Denmark) and anti-human nestin monoclonal antibody $(1: 50 ; 10 \mathrm{C} 2$, Santa Cruz Biotechnology, Santa Cruz, CA, U.S.A.) were used as primary antibodies.

Three fields were randomly selected under high magnification from the immunostained tumor margin samples using a light microscope, and microvascular densities were calculated by adding the numbers of CD34- and nestin-positive blood vessels in each field (Fig. 1). These were missing elastic lamina and forming tubular structures. The correlations between microvascular densities and clinical pathological factors, and between microvascular densities and patient prognoses were calculated. Statistical assessments were made using the MannWhitney test, in which $P<0.05$ was defined as being statistically significant. Relapse-free survival and overall survival included the period following the operations until death or until observations had been completed.

\section{Results}

Relationship between microvascular density and clinicopathological factors 
Table 1. Clinicopathological characteristics of the patients

\begin{tabular}{|c|c|c|c|c|}
\hline & & & $\mathrm{n}$ & $\%$ \\
\hline \multirow[t]{3}{*}{ Age } & \multicolumn{4}{|c|}{ (range $30-88$, mean 60.4 ) } \\
\hline & \multicolumn{2}{|l|}{$<50$} & 36 & 25 \\
\hline & \multicolumn{2}{|l|}{$\geqq 50$} & 108 & 75 \\
\hline \multirow[t]{3}{*}{ Surgery } & \multicolumn{2}{|l|}{ tumorectomy } & 2 & 1.4 \\
\hline & \multicolumn{2}{|l|}{$\mathrm{BCT}+$ radiotherapy } & 31 & 21.5 \\
\hline & \multicolumn{2}{|l|}{ mastectomy } & 111 & 77.1 \\
\hline \multirow{5}{*}{$\begin{array}{l}\text { Histological } \\
\text { type }\end{array}$} & \multicolumn{2}{|l|}{ NIDC } & 3 & 2.1 \\
\hline & \multicolumn{2}{|l|}{ IDC } & 47 & 32.6 \\
\hline & Special type & pap-tub & 20 & 13.9 \\
\hline & & sol-tub & 59 & 41.0 \\
\hline & & sci & 15 & 10.4 \\
\hline \multirow[t]{3}{*}{ Tumor size } & \multicolumn{2}{|l|}{$\mathrm{T} 1$} & 60 & 42.3 \\
\hline & \multicolumn{2}{|l|}{$\mathrm{T} 2$} & 77 & 54.2 \\
\hline & \multicolumn{2}{|l|}{$\mathrm{T} 3$} & 5 & 3.5 \\
\hline \multirow[t]{2}{*}{ Nodal status } & \multicolumn{2}{|l|}{ negative } & 79 & 56.8 \\
\hline & \multicolumn{2}{|l|}{ positive } & 60 & 43.1 \\
\hline \multirow{2}{*}{$\begin{array}{l}\text { Distant } \\
\text { metastases }\end{array}$} & \multicolumn{2}{|l|}{ negative } & 114 & 79.2 \\
\hline & \multicolumn{2}{|l|}{ positive } & 30 & 20.8 \\
\hline \multirow[t]{2}{*}{ ly } & \multicolumn{2}{|l|}{ negative } & 92 & 70.2 \\
\hline & \multicolumn{2}{|l|}{ positive } & 39 & 29.8 \\
\hline \multirow{3}{*}{$\begin{array}{r}\text { Nuclear } \\
\text { grade }\end{array}$} & \multicolumn{2}{|l|}{1} & 72 & 55.8 \\
\hline & \multicolumn{2}{|l|}{2} & 23 & 17.8 \\
\hline & \multicolumn{2}{|l|}{3} & 34 & 26.4 \\
\hline \multirow[t]{2}{*}{ ER } & \multicolumn{2}{|l|}{ negative } & 60 & 46.5 \\
\hline & \multicolumn{2}{|l|}{ positive } & 69 & 53.5 \\
\hline \multirow[t]{2}{*}{ PgR } & \multicolumn{2}{|l|}{ neative } & 63 & 48.8 \\
\hline & positive & & 66 & 51.2 \\
\hline
\end{tabular}

BCT: breast conserving therapy, NIDC : Noninvasive ductal carcinoma, IDC : invasive ductal carcinoma, pap-tub : papillotubular carcinoma, sol-tub : solid-tubular carcinoma, sci : scirrhous carcinoma, ly: lymphatic vessel invasion

ER : estrogen receptor, $\mathrm{PgR}$ : progesterone receptor

The following clinicopathological factors were assessed to determine whether these correlated with the microvascular density of the tumor: age, tumor diameter, lymph node metastasis, distant metastasis, lymphatic vessel invasion, nuclear grade (NG), estrogen receptor (ER), and progesterone receptor (PgR) (Table 2).

Regarding age, separate assessments were made for patients younger than 50 years of age and for those who were 50 years of age or older. Although the microvascular density was low in the older group of patients (50 years of age or older), no significant differences in microvascular density were observed. 


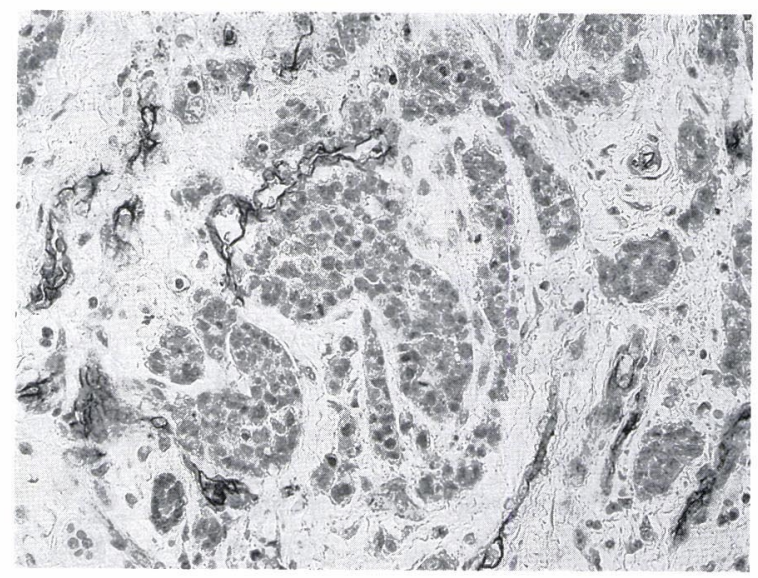

Fig. 1. Microvessels were highlighted by CD34 immunostaining

Table 2. Dlinicopathological factors and microvessel density (MVD)

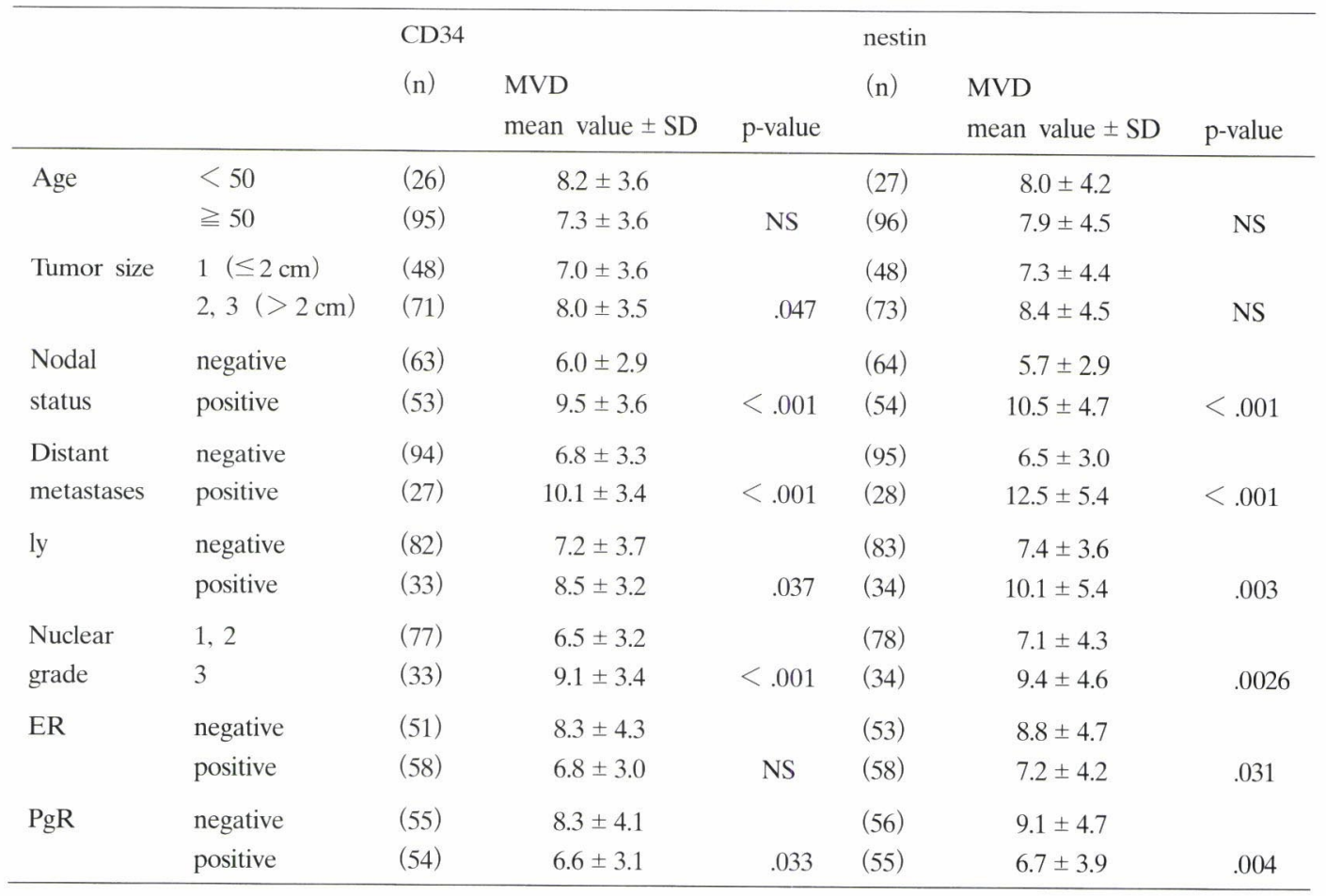

ly: lymphatic vessel invasion, ER : estrogen receptor, PgR: progesterone receptor, NS : not significant

To assess the relationship with tumor diameters, separate assessments were made for tumors with different TNM classifications, and included T1 tumors $(<2 \mathrm{~cm})$, T2 tumors (2$5 \mathrm{~cm})$, and T3 tumors $(>5 \mathrm{~cm})$. Microvascular densities were significantly higher in tumors with large diameters in CD34-stained samples only. 

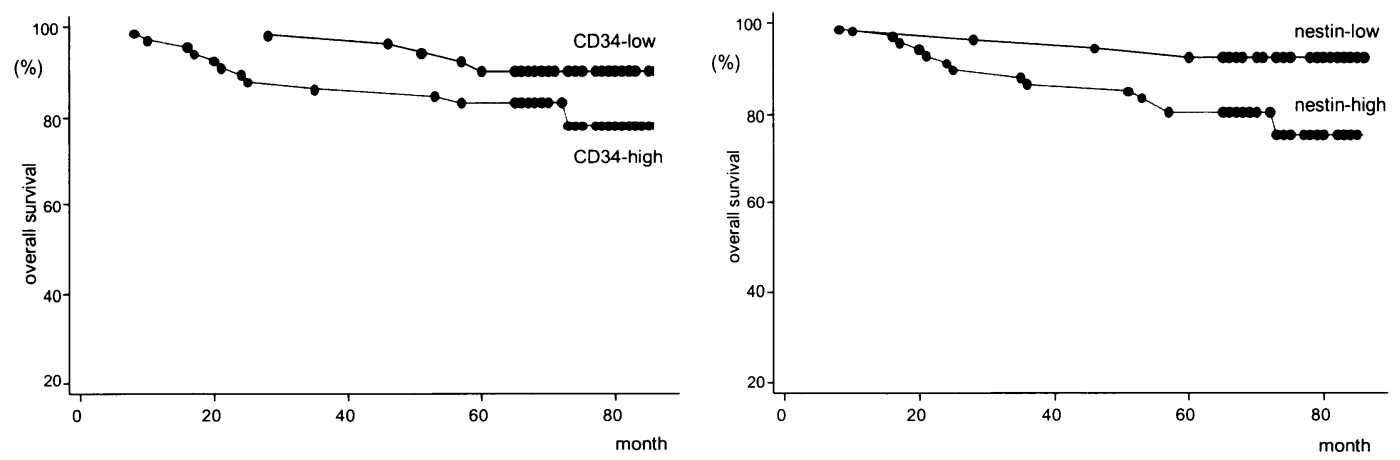

Overall survival was significantly shorter in the high value group in comparison with the low value group with both CD34 and nestin. $(p<0.05)$

Fig. 2. Overall survival of subgroups (CD34 low/high and nestin low/high)

Microvascular densities were significantly higher in patients with lymph node metastases and distant metastases in both CD34- and nestin-stained samples. Similarly, microvascular densities were also significantly higher in patients with positive lymphatic vessel invasion in both CD34- and nestin-stained samples.

To assess the nuclear grade (NG) of the tumor, separate assessments were made for tumors with different nuclear grades as described in the Breast Cancer Handling Conventions in Japan (Vol. 15), and included NG1 +2 and NG3 tumors. Microvascular densities were significantly higher in NG3 tumors in both CD34- and nestin-stained samples.

Separate assessments were also made for the estrogen (ER) and progesterone (PgR) hormone receptors. Negative results were defined as those in which the ratio of positively stained cells was less than $10 \%$, and positive results as those with a ratio of $10 \%$ or higher. Significant differences in microvascular densities were observed in nestin-positive samples expressing ER, and in CD34- and nestin-positive samples expressing PgR.

\section{Relationship between microvascular density and overall survival}

The mean values of the microvascular densities calculated with CD34 and nestin were 7.51 and 7.91, respectively. When the relationship between these values and overall survival (OS) was studied separately for the low-value group (less than 7) and the high-value group ( 7 or more), the OS was significantly shorter in the high-value group with both CD34 and nestin (Fig. 2).

\section{Discussion}

A 1991 study of 49 primary breast cancer cases, Weidner et al ${ }^{2)}$ reported that microvascular density is related to lymph node metastasis and distant metastasis. Since then, many studies have described the correlation between microvascular density and metastasis and patient prognosis in breast cancer $^{2-12)}$. However, some reports have found no correlation between microvascular density and cancer progression ${ }^{5.11 .13-15)}$. The cause of this discrepancy can possibly be attributed to the lack of a common method for measuring microvascular densities ${ }^{12)}$. Specifically, this discrepancy may be caused by differences in the areas where the vascular densities are measured and by the vascular endothelial markers used. Kato 
et $a l^{16)}$ evaluated the different sites used for measuring microvascular densities using three methods: AMC (average microvessel count: the entire margin of the tumor); CMC (central microvessel count: 6 sites at the center of the tumor); and HMC (highest microvessel count : 3 hot spots), and reported that AMCs were useful in the assessment of neovascularization. However, only one vascular endothelial marker, Factor VIII, was used in their study.

In the present study, two vascular endothelial markers were used: CD34 and nestin. CD34 is widely used as a vascular endothelial marker to assess microvascular densities in various carcinomas including breast cancer ${ }^{5.13,17-19)}$. In contrast, nestin is usually used as a marker for stem cells and progenitor cells, which differentiate into various kinds of cells. However, nestin has been gaining attention recently as a useful vascular endothelial marker ${ }^{20,21)}$, and has been used to assess microvascular densities in gastric and colonic cancer $^{18,19)}$.

Based on these previous studies, we measured microvascular densities in tumor margins using CD34 and nestin, and investigated whether there was a correlation between microvascular density and metastasis and patient prognosis. Our results demonstrate that microvascular densities were significantly higher in patients with lymph node metastases and distant metastases compared to those without, based on the results of both CD34 and nestin immunostaining. We believe that this result reaffirms the fact that neovascularization contributes to the metastatic growth of tumors, and supports the usefulness of the AMC microvascular density measurement method reported by Kato et $a l^{7)}$. In addition, it appears that it is not necessary to use a specific vascular endothelial marker to measure microvascular densities.

In the present study, the clinicopathological factors that were significantly correlated with microvascular densities were the presence of lymph node metastases and distant metastases, lymphatic duct invasion, tumor diameter, nuclear grade, presence of hormone receptors, and overall survival. These results emphasize that microvascular density measurements are an effective indicator of metastasis and patient prognosis in breast cancer patients, just as they are in other carcinomas. In contrast, the correlation between microvascular densities and hormone receptors is considered to be an aspect specific to breast cancer. Furthermore, neovascularization is induced by various factors associated with cancer proliferation ${ }^{22)}$, and the fact that microvascular densities tended to be lower in elderly patients in this study corresponds to reports stating that neovascularization is suppressed by decreases in estrogen concentrations $^{23.24)}$. Although further studies must be conducted to gain a better understanding of breast cancer and to develop treatment applications for breast cancer in relation to microvascular densities, it will also be necessary to consider the assessment of breast cancer-specific factors that are associated with the induction of neovascularization.

\section{Conclusion}

A significant correlation was observed between microvascular densities, which were measured using CD34 and nestin immunostaining, and metastasis and disease prognosis in the breast cancer cases treated in our hospital.

\section{References}

1) Folkman J : Tumor angiogenesis : therapeutic implications. N Engl J Med 285 : 1182-1186 (1971)

2) Weidner N, Semple JP, Welch WR and Folkman J : Tumor angiogenesis and metastasis-correlation in invasive breast carcinoma. New Engl J Med $324: 1-8$ (1991) 
3) Weidner N, Folkman J, Pozza F, Bevilacqua P, Allred N, Moore DH, Meli S and Gasparini G: Tumor angiogenesis : a significant and independent prognostic indicator in early-stage breast carcinoma. $J$ Natl Cancer Inst 84: $1875-1887(1992)$

4) Gasparini G, Toi M, Verderio P, Ranieri G, Dante S, Bonoldi E, Boracchi P, Fanelli M and Tominaga T: Prognostic significance of $\mathrm{p} 53$, angiogenesis, and other conventional features in operable breast cancer: subanalysis in node-positive and node-negative patients. Int J Oncol $12: 1117-1125$ (1998)

5) Kumar S, Ghellal A, Li C, Byrne G, Haboubi N, Wang JM and Bundred N : Breast carcinoma : vascular density determinated using CD105 antibody with tumor prognosis. Cancer Res 59:856-861 (1999)

6) Guidi AJ, Berry DA, Broadwater G, Perloff M, Norton L, Barcos MP and Hayes DF : Association of angiogenesis in lymph node metastases with outcome of breast cancer. J Natl Cancer Inst 92:486-492 (2000)

7) Kato T, Kameoka S, Kimura T, Soga N, Abe Y, Toshio N and Kobayashi M: Angiogenesis as a predictor of long-term survival for 377 Japanese patients with breast cancer. Breast Cancer Res Treat 70:65-74 (2001)

8) Kato T, Kameoka S, Kimura T, Nishikawa $\mathrm{T}$ and Kobayashi $\mathrm{M}$ : The combination of angiogenesis and blood vessel invasion as a prognostic indicator in primary breast cancer. Br J Cancer 88 : 1900-1908 (2003)

9) Tsutsui S, Kume $M$ and Era S: Prognostic value of microvessel density in invasive ductal carcinoma of the breast. Breast Cancer $10: 312-319$ (2003)

10) Nieto Y, Woods J, Nawaz F, Baron A, Jones RB, Shpall EJ and Nawaz S: Prognostic analysis of tumour angiogenesis, determined by microvessel density and expression of vascular endothelial growth factor, in highrisk primary breast cancer patients treated with high-dose chemotherapy. Br J Cancer 97 : 391-397 (2007)

11) Uzzan B, Nicolas $P$, Cucherat $M$ and Perret G: Microvessel density as a prognostic factor in women with breast cancer: A systematic review of the literature and meta-analysis. Cancer Res 64:2941-2955 (2004)

12) Fox SB and Harris A : Histological quantitation of tumour angiogenesis. APMIS $112: 413-430$ (2004)

13) Paradiso A, Ranieri G, Silvestris N, Naccarato GB, Mangia A, Leone B, Vallejo C, Simone G, Schittulli F and Lena MD : Failure of primary breast cancer neoangiogenesis to predict pattern of distant metastasis. Clin Exp Med $1: 127-132$ (2001)

14) Vincent-Salomon A, Carton M, Zafrani B, Freneaux P, Nicolas A, Massemin B, Fourquet A, Clough K, Pouillart $\mathrm{P}$ and Sastre-Garau X: Long term outcome of small size invasive breast carcinomas independent from angiogenesis in a series of 685 cases. Cancer $92: 249-256$ (2001)

15) Ludovini V, Sidoni A, Pistola L, Bellezza G, Angelis VD, Gori S, Mosconi AM, Bisagni G, Cherubini R, Bian AR, Rodino C, Sabbatini R, Mazzocchi B, Bucciarelli E, Tonato M and Colozza M: Evaluation of the prognostic role of vascular endothelial growth factor and microvessel density in stages I and II breast cancer patients. Breast Cancer Res Treat $81: 159-168$ (2003)

16) Kato $T$, Kimura $T$, Ishii $N$, Fujii $A$, Yamamoto $K$, Kameoka $S$, Nishikawa $T$ and Kasajima $T$ : The methodology of quantitation of microvessel density and prognostic value of neovascularization associated with long-term survival in Japanese patients with breast cancer. Breast Cancer Res Treat $53: 19-31$ (1999)

17) Hansen S, Grabau DA, Sorensen FB, Bak M, Vach W and Rose C: The prognostic value of angiogenesis by Chalkley Counting in a confirmatory study design on 836 breast cancer patients. Clin Cancer Res $6: 139-146$ (2000)

18) Kim HS, Kang HS, Messam CA, Min KW and Park CS : Comparative evaluation of angiogenesis in gastric adenocarcinoma by nestin and CD34. Appl Immunohistochem Mol Morphol 10 : 121-127 (2002)

19) Teranishi N, Naito Z, Ishiwata T, Tanaka N, Furukawa K, Seya T, Shinji S and Tajiri T: Identification of neovasculature using nestin in colorectal cancer. Int J Oncol 30 : 593-603 (2007)

20) Klein T, Ling Z, Heimberg H, Madsen OD, Heller RS and Serup P: Nestin is expressed in vascular endothelial cells in the adult human pancreas. $J$ Histochem Cytochem $51: 697-706$ (2003)

21) Amoh Y, Yang M, Li L, Reynoso J, Bouvet M, Moossa AR, Katsuoka K and Hoffman RM : Nestin-linked green fluorescent protein transgenic nude mouse for imaging human tumor angiogenesis. Cancer Res $65: 5352$ 5357 (2005)

22) Toi M, Sasaki K, Bando H, Matsumoto $\mathrm{T}$ and Saji S : Nyuugan no shinten to kekkan no kakawari. Jikken igaku 20 : 1133-1139 (2002) (in Japanese)

23) Nakamura J, Savinov A, Lu Q and Brodie A : Estrogen regulates vascular endothelial growth/permeability factor expression in 7, 12-Dimethylbenz (a) anthracene induced rat mammary tumors. Endocrinology 137:55895596 (1996)

24) Johns A, Freay AD, Fraser W, Korach KS and Rubanyi G: Disruption of estrogen receptor gene prevents 17 $\beta$ estragiol induced angiogenesis in transgenic mice. Endocrinology 137 : 4511-4513 (1996)

[Received January 29, 2008 : Accepted February 1, 2008] 